\title{
Challenges and Opportunities in Diagnosis and Management of Generalized Anxiety Disorder in Primary Care
}

\author{
Mehtap Kartal \\ Dokuz Eylul University, Faculty of Medicine, Department of Family Medicine \\ Turkey
}

\section{Introduction}

It is known that General Anxiety Disorder (GAD), falling into the category of anxiety disorders with symptoms of anxiety, worry and apparent alertness, displays a fairly constant prevalence in the general population. Its lifelong prevalence in the general population is $5 \%$ according to the criteria of DSM and $6.5 \%$ according to broader criteria of ICD-10.

Among anxiety disorders, GAD patients often consult primary care physicians (PCPs) for their treatment. An international study conducted by the World Health Organization (WHO) found the frequency of GAD in primary health care at $14.9 \%, 3.7 \%$ and $0.9 \%$ in Greece, Italy and Turkey respectively. Despite these different figures among countries which are thought to emerge from structural differences of primary health care services, it was found out that the point prevalence of GAD in primary care was much higher $(7.9 \%)$ than that of the general population. Through reanalysis of WHO's data, it was also shown that $25 \%$ of these patients have pure GAD without any comorbidity. In light of this data, it can be concluded that GAD is the most frequent mental disorder after depression in primary care, and that patients favour primary health care services for their treatment.

The comorbidity of GAD patients with other psychiatric disorders brings about an increase in the frequency of the health care system use, with longer periods of hospitalization, more frequent use of diagnostic tests and medication, and therefore, a heavy financial burden. This, in turn, implies more serious family problems and prolonged absence from work. There is abundant evidence showing that GAD decreases the quality of life considerably due to invalidity and disability.

It is reported that patients complain of physical symptoms more often than psychological, and worry is cited as the main problem for only $13 \%$ of GAD patients in primary care. The patients with GAD mostly consult primary care for aches, sleep problems and somatic problems. Somatic complaints of patients usually appear in the form of chronic medical conditions such as chest pain, chronic fatigue syndrome, irritable bowel syndrome and hypertension, diabetes and cardiac diseases. This is an important factor that complicates the accurate diagnosis of patients and also delays their treatment. The period between the time when the first symptoms of GAD appear and the time of the patient's consultation with the family physician or its equivalent can last for up to one year. Furthermore, it can take as 
long as seven years for the first consultation with the expert at an anxiety clinic. It was observed that about one third of GAD patients were not given a proper psychological diagnosis by family physicians.

Stigmatization is an important factor in insufficient diagnosis and this can account for why a significant number of patients do not express their emotional problems to their physicians. Patients with GAD are often unsuccessful at identifying that their symptoms as related to psychological disorders. People who minimize and normalize their symptoms are mostly young male patients and it is reported that they receive fewer correct diagnoses.

Along all these patient-related factors, it is clear that there are huge discrepancies in physicians' diagnostic skills, emerging from their knowledge, abilities and approaches. Longer consultation periods do not increase chance of correct diagnosis of diseases either. However, while empathy, interest in psychiatry and asking questions about family and domestic problems can increase the chance for an accurate diagnosis, coexisting organic diseases complicate it further. In a study conducted over a group of patients who mostly rely on using primary care services, GAD was found to be the disease which was most difficult to diagnose and caused most frustration for the physicians. It could be argued that this seriously affects physicians' skills to diagnose and treat their patients appropriately. It is apparent that physicians require tools to use for diagnosis.

The low rate of recognition and diagnosis of GAD in primary care presents a barrier for appropriate treatment and referrals needed for it. However, primary care physicians are the group with access to the largest body of patients.

The problems encountered in primary care diagnosis and management of anxiety in GAD are multifaceted and multiphase, which complicates the solutions as well. First of all, social interventions, including education campaigns which would improve society's approach to mental problems and decrease stigmatization, are required. Furthermore, increasing awareness of primary care physicians and equipping them with proper scanning tools is a necessity. Finally, developing national diagnosis and treatment guidelines, and promoting evidence based medical practice is also of great importance.

\section{Epidemiology of GAD}

Before the 1980s, Generalized Anxiety Disorder (GAD) was labelled as 'anxiety neurosis' characterized by excessive worrying and marked symptoms of hypervigilence and anxiety. GAD was first conceptualized in the Diagnostic and Statistical Manuel of Mental Disorders-III (DSM) in 1980 and its diagnostic criteria have changed since then. The current criteria in DSM-IV (Table 1) and the International Classification of Diseases-10 (ICD) (Table 2) for GAD differ considerably with ICD-10 listing a broader spectrum of symptoms. The differences in the understanding GAD between Europe and the United States predominantly based on the fact that ICD-10 is preferred in Europe, while DSM-IV is preferred in the United States (Wittchen \& Hoyer, 2001; Lieb et al., 2005). These preferences have a substantial impact on the epidemiological results. The most likely lifetime prevalence for GAD in the general population is 5\% (ranges between $0.8-21.7 \%$ with different assessment tools in different countries) with DSM criteria and slightly higher, 6.5\%, with ICD-10 criteria (Bijl et al., 1998; Wittchen \& Hoyer, 2001; Lieb et al., 2005; Mergl et al., 2007; Serrano-Blanco et al., 2010). 
A. Excessive anxiety and worry (apprehensive expectation), occurring more days than not and for at least 6 months, about a number of events or activities (such as work or school performance)

B. The person finds it difficult to control the worry

C. The anxiety and worry are associated with three (or more) of the following six symptoms (with at least some symptoms present for more days than not for the past 6 months). Note: only one item is required in children

(1) restlessness or feeling keyed up or on edge

(2) being easily fatigued

(3) difficulty concentrating or mind going blank

(4) irritability

(5) muscle tension

(6) sleep disturbance (difficulty falling or staying asleep, or restless unsatisfying sleep)

D. The focus of the anxiety and worry is not confined to features of an Axis I disorder. E.g., the anxiety or worry is not about having a panic attack (as in panic disorder), being embarrassed in public (as in social phobia), being contaminated (as in obsessive compulsive disorder), being away from home or close relatives (as in separation anxiety disorder), gaining weight (as in anorexia nervosa), having multiple physical complaints (as in somatisation disorder), or having serious illness (as in hypochondriasis), and the anxiety and worry do not occur exclusively during posttraumatic stress disorder

E. The anxiety, worry, or physical symptoms cause clinically significant distress or impairment in social, occupational, or other important areas of functioning.

F. The disturbance is not due to the direct physiological effects of a substance (e.g, a drug of abuse, a medication) or general medical condition (e.g., hyperthyroidism) and does not occur exclusively during a mood disorder, a psychotic disorder or a pervasive developmental disorder

Table 1. DSM-IV criteria for generalized anxiety disorder

Anxiety that is generalized and persistent but not restricted to, or even strongly predominating in, any particular environmental circumstances (i.e. it is "free-floating"). The dominant symptoms are variable but include complaints of persistent nervousness, trembling, muscular tensions, sweating, light-headedness, palpitations, dizziness, and epigastric discomfort. Fears that the patient or a relative will shortly become ill or have an accident are often expressed.

Anxiety:

neurosis

reaction

state

Excludes: neurasthenia (F48.0)

Table 2. ICD-10 Criteria for Generalized anxiety disorder (F41.1) 
The data, both European and non-European, suggests that GAD is most common among older age groups, unlike other anxiety disorders. It also shows that the likelihood of diagnosis of GAD increases with age: for women after the age of 35, and for men after the age of 45 . It is relatively rare in the first two decades of life, with lower prevalence rates among adolescents and young adults. However, the age of onset has a bimodal distributionGAD onset occurs earlier if it is the primary presentation and later if it is secondary (Culpepper, 2002; Lieb et al, 2005). GAD occurs twice as often in women as men, with total lifetime prevalence rates of 6.6\% and 3.6\%, respectively (Carter et al., 2001; Allgulander, 2006). Other factors significantly associated with GAD are determined to be: discontinued marriage (separated, widowed, or divorced), unemployed or being a house-wife while urbanicity, low income, fewer years of education, more life difficulties, and chronic medical disorders and religion showed limited associations (Wittchen \& Hoyer, 2001; Young et al., 2001)

Similarly to patients that suffer of panic disorders, GAD patients often consult primary care physicians for their treatment. An international study conducted by the World Health Organization (WHO) found the frequency of GAD in primary health care at $14.9 \%, 3.7 \%$ and $0.9 \%$ in Greece, Italy and Turkey respectively. Despite these different figures among countries which are thought to emerge from structural differences in primary health care services, it was found out that the point prevalence of GAD in primary care was much higher $(7.9 \%)$ than that of the general population (Ustun \& Sartorius, 1995). Through reanalysis of WHO's data, it was also shown that $25 \%$ of these patients have pure GAD without any comorbidity (Lieb et al., 2005). The GADIS study determined the prevalence of pure GAD at $4.1 \%$, and all GAD at $8.3 \%$ in primary care, while Kroenke et al. found the prevalence of GAD in primary care to be 7.6\% (Ansseau et al., 2005; Kroenke et al., 2007). In light of this data, it can be concluded that GAD is the most frequent mental disorder after depression in primary care, and that patients favour primary health care services for their treatment.

\section{Presentation and recognition of GAD in primary care}

GAD symptoms wax and wane over time, with exacerbations of acute anxiety to response stress. Many patients with GAD readily report "I've been a worrier all my life". Studies support its episodic pattern with remission and recurrence periods evident for many years. (Wittchen \& Hoyer, 2001; Allgulander, 2006).

GAD is a disabling condition and a social disability as severe as chronic somatic disorders such as arthritis, hypertension, asthma, and diabetes (Maier et al., 2000; Wittchen \& Hoyer, 2001; Kessler et al., 2001; Roy-Byrne Wagner, 2004 ; Lieb, 2005). Wittchen et al. have shown that only $13 \%$ of GAD patients in primary care identify anxiety as the primary problem (Wittchen, 2002). Mostly, patients complain of somatic and sleeping problems (Wittchen \& Hoyer, 2001). Accompanying symptoms include muscle tension, headache, muscle aches, restlessness, irritability, gastrointestinal symptoms, and difficulty in concentrating, fatigue, insomnia (Shearer, 2007). Patients are unlikely to directly and openly complain of anxiety symptoms. Cardiac and gastrointestinal symptoms of anxiety deserve special attention so as not to be misinterpreted in differential diagnosis and to avoid high costs of potential unnecessary screening for accurate diagnosis. GAD was determined to be primary diagnosis among $20 \%$ of patients with an atypical chest pain; $55 \%$ of patients with chest pain \& normal coronary arteries; and $50 \%$ of patients seeking a cardiac evaluation (Roy-Byrne Wagner, 2004). Similarly, - in patients with inflammatory bowel syndrome GAD was showed to be in 
high prevalence (Roy-Byrne Wagner, 2004). A longitudinal study that determines the underrecognition of mental disorders showed that $18 \%$ of patients that had severe symptoms of depression or anxiety according to the general health questionnaire had never received a diagnosis from their general practitioners (GPs) (Kessler et al., 2002).

In another study, first three common reasons for the GP visit were listed as oto-rhinolaryngology (ORL), cardiovascular, and rheumatologic problems. However, a psychiatric problem was mentioned only in $5.4 \%$ of the cases. On the other hand, for the same sample, the prevalence of a psychiatric disorder was found $42.5 \%$, and GAD prevalence was $10.3 \%$, detected by PRIME-MD (Ansseau et al., 2004). A different study showed that $69.6 \%$ of the patients reporting anxiety/depression as a reason for consulting their GP had GAD (Ansseau et al., 2005).

Not only patients and primary care physicians' factors, but also the waxing and waning nature of GAD, leading to a "discrepancy" between primary reasons for visiting the GPs and actual diagnosis is important for recognizing GAD accurately (Ansseau et al., 2004; Tylee \& Walters, 2007).

Chronic nature of GAD with remissions and recurrences, symptoms do not meet the criteria in periods of recovery between episodes and substantial overlap with other medical and psychological disorders may make it difficult to easily detect it (Kroenke et al., 1997, RoyByrne Wagner, 2004; Allgulander, 2006). Major depressive disorder is seen in at least onethird of primary care patients with GAD (Carter et al., 2001; Stein, 2003). Comorbidity with panic disorder, social phobia and specific phobia, and post-traumatic stress disorder is also common. Comorbidity is generally associated with increased severity and persistence of the disorders (Allgulander, 2006). However, GAD patients were found to be diagnosed with two or more comorbid disorders more often than any other disorder (Carter et al., 2001). Rodrigues et al. showed that primary care patients in the study population showed as much Axis I comorbidity as psychiatric treatment-seeking population. This is an important finding that questions previous assumptions about treatment-seeking in mental health settings as an indication of illness severity (Rodrigues et al.; 2004).

It is known that there is a wide variation in the ability of primary care physicians to diagnose GAD due to differences in knowledge, skills, and attitudes. Not only factual knowledge but also clinical skills, particularly communication skills and interview techniques, are important in the management of psychiatric disorder. Other obstacles have been mentioned: competing demands on PCPs time to interview patients within the limit of typical 15-min clinical encounters, frequent somatisation of mental disorders, underlying comorbidity, and preoccupation of an organic disease. However, empathy, an interest in psychiatry and asking about family and problems at home can help with the recognition (Ansseau et al., 2004; Rollman et al., 2005; Allgulander, 2006; Tylee \& Walters, 2007). Harman et al. reported that vast majority of PCPs' diagnosis were branded "anxiety, unspecified". They concluded that this may reflect that the symptoms of primary care patients do not fulfil a specific diagnosis like GAD, or current description of anxiety disorders in commonly used classifications is too complicated to be easily applied by PCPs (Harman et al., 2002).

With regards to the patients, this discrepancy can be due to the considerable resistance to a psychiatric diagnosis and reluctance to discuss their psychiatric condition for the fear of stigmatization, and may account for $45 \%$ of people failing to share their emotional problems with their physicians (Cape \& McCullech, 1999; Tylee \& Walters, 2007). Another factor is that patients do not consider their psychiatric symptomatology as sufficiently unusual or 
troublesome to be mentioned until the underlying anxiety is identified (Harman et al., 2002; Ansseau et al., 2004). Kessler et al. found different styles of symptom attribution, and showed that patients who attribute a psychological cause are more likely to be recognized when compared to patients who normalize or minimize their symptoms. Normalisers were determined as younger and male patients (Kessler et al., 1999). Harman et al. argued that reimbursement issues or concerns over a patient's willingness to be diagnosed with an anxiety disorder could also be possible explanations (Harman et al., 2002). Besides these, a qualitative study had shown that patients were open to suggestions from their GPs or otherwise. Furthermore, several described their GPs as "marvellous" or "has never let me down". They believed it was helpful to talk to someone about their problem; however the search for this person was seen as difficult. Patients expressed the need for an easier access to professional help, suggesting their GPs should be more active in referrals, checking up on the patients' progress through phone calls, follow-up sessions, and home visits. Patients also expressed concern about interfering their GP's busy schedule, because of GP's involvement with more pressing medical cases. However some also conserve their hope for their GPs to do more than prescribe drugs, waiting for encouragement of to disclose their emotional or psychological problems. Another concern of theirs was the waiting time, since they wish to speak to someone at the moment they are feeling bad, instead of waiting for appointments (Kadam et al., 2001).

Since GAD is highly prevalent in the primary care setting, patients with the disorder are likely to be high users of primary care health services, both in terms of the frequency of visits and the sheer number of patients contacting primary care providers because of problems associated with the disorder (Wittchen \& Hoyer, 2001). Young et al. showed that during a 1-year period, $84.3 \%$ of individuals with an anxiety disorder only visit PCPs (Young et al., 2001). Harman et al. found the proportion of visits to PCPs as 46.5-48.2\%, which still holds true today. They also reported that anxiety disorder diagnose were recorded more often during visits where the physician had seen the patient before, and a depression diagnosis had also been recorded during that same visit (Harman et al., 2002). Patients with pure GAD are 1.6 times more likely to have four or more visits to PCPs than patients without GAD or major depressive episodes (MDE) (Wittchen, 2002). Bélanger et al. determined that patients with positive screening for GAD reported more annual medical visits (5.3 versus 3.4) than other patients, and $44.5 \%$ of the positive screening group reported consulting a family physician five times or more yearly, compared with $20.0 \%$ in the negative screening group. However, they did not report consulting other resources more often, suggesting that patients with GAD might mostly seek treatment from PCPs (Bélanger et al., 2005). Kronke et al. determined the self-reported 2.9 (2.2-3.6) physician visits in the preceding 3 months (Kroenke et al., 2007).

GAD patients have to be identified so they can be properly treated. Wagner et al. found that family physicians (FPs) diagnosed 39\% of cases correctly while $29.3 \%$ left with no psychological diagnosis (Wagner et al., 2006).

There is an obvious need for tools that will help PCPs in diagnosing and monitoring GAD patients. There are several recommended specifically for GAD, such as Generalized Anxiety Disorder Inventory (GADI), GAD-7; tools for severity assessment such as Hamilton Anxiety Scale (HAM-A); and tools for measurement of functional impairment due to anxiety such as Overall Anxiety Severity and Impairment Scale (OASIS). Web-based screening can also be a choice as being cost-efficient (Allgulander, 2009; Katzman, 2009; Roy-Byrne, 2009). Ruiz et al. showed that GAD-7 highly correlated not only with specific anxiety measures but also 
with disability measures, which can be used for exploring the level of disability in GAD patients in primary care setting (Ruiz et al., 2011).

In the absence of systematic screening, 30-40\% of anxiety and depression patients are identified in primary care setting. There are studies showing evidence for and against the screening. Some reviews point that screening alone does not improve patient's outcome. However, others concluded that screening has increased benefits when combined with effective treatment and follow up. A barrier for screening is that tools' length, specificity for a single disorder or both. Means-Christensen et al. recommended Anxiety and Depression Detector (ADD) as screening instrument for anxiety and depressive disorders in primary care. ADD's sensitivity and specificity ranges between $0.87-1.0$ and $0.42-0.68$, respectively (Means-Christensen et al.; 2001). Rollman et al. suggested that PRIME-MD can be used in identifying primary care patients with GAD as a part of broader strategy to improve quality of care for GAD patients (Rollman et al., 2005).

PCPs have to use their advantage of continuous contact and communication skills for efficient history taking. To aid accurate diagnosis and to rule out other possible diagnosis, both the patient's and the family's histories should be assessed carefully. Recent life events and other health problems including depression, substance or alcohol abuse and dependence should be noted. Multiple visits to PCPs, consultations with different specialists such as gastroenterologists, and consultations that end with no definite diagnosis should be carefully considered (Katzman, 2009).

\section{Burden of GAD in primary care}

There is abundant evidence not only on the impairment and disability but also the reduced quality of life in GAD patients. Hospitalization and loss of productivity were the two major components of costs both in patients with and without comorbidity. Health care utilization rates were higher among those with comorbid GAD patients compared to pure GAD (Lieb et al., 2005).

The burden of disability is clearly greater as the number of comorbidities increases (Wittchen et al., 2002; Kroenke et al., 2007; Löwe et al., 2008). Majority of pure GAD patients $(66.7 \%)$ report impairment of occupational functioning, and selfreported disability days were 9.9 days in the preceding month. This was reported as 15.3 days for patients with pure MDE, and 16.5 days for comorbid GAD and MDE (Witthchen et al., 2002). Kroenke et al. reported in their study that self-reported disability days of the patients with pure GAD during the previous 3 months were 18.1 days (Kroenke et al., 2007). A recent study comparing the functional impact of different anxiety disorders and their combinations showed that disability in GAD was significantly less present in comparison with other anxiety disorders. However, all measures of functioning and disability, except for physical functioning, showed substantial impairment in the overall sample when compared to general population. (Sherborne et al., 2010). ESEMed study found that GAD is associated with substantial level of disability as well as a decrease in the quality of life (Alonso et al., 2004). Revicki et al. showed that anxiety symptoms of GAD patients in primary care settings were associated with impairments in generic health status, disability, disease-specific quality of life, and preference-based measures of health-related quality of life (Revicki et al., 2008). In the WHO Primary Care study, $27 \%$ of the patients with GAD reported moderate or severe social disability, with a mean loss of 4.6 work days due to disability in the month preceding the assessment. When GAD was accompanied by major depression, the mean number of lost work days increased to 8.0 days (Lieb et al., 2005). 
Presence of GAD, especially comorbidity with major depression, leads substantial impairment of social, professional, and family conditions rated by Sheehan disability scale (Wittchen \& Hoyer, 2001; Ansseau et al., 2005; Olfson and Gameroff, 2007). The most serious effects of GAD were observed in the subscales for emotional role limitations and physical health role limitations (Stein, 2003). In a study where Medical Outcomes Study Short Form20 was used to determine functioning in GAD patients, all six domains of the scale were determined as impaired (Kroenke et al., 2007).

Andlin-Sobocki and Wittchen reported total direct medical costs at $€ 1958$ and $€ 3194$ and indirect costs at $€ 969$ and $€ 1659$ for GAD and GAD with comorbidity, respectively (AndlinSobocki and Wittchen, 2002). Olfson and Gameroff found that patients with GAD had a significantly higher median medical cost than patients without GAD (\$2775 versus \$1448), and patients with GAD and high pain interference had the highest mean predicted medical cost, $\$ 42.620$. They also showed that GAD patients had a greater likelihood of making an emergency department visit (Olfson and Gameroff, 2007).

\section{Management of GAD in primary care}

The proper management of GAD in the primary care settings should not include only pharmacotherapy or psychotherapy but also education of patients and their families, counselling for lifestyle changes, as well as beneficial, continuous support, insomnia management, and development of coping strategies to manage their worries (Culpepper, 2002). There is no evidence-based approach for the combination of different treatment options for GAD patients so there is a need for further researches including large study populations targeted on current practice (Allgulander, 2009).

Education about GAD for both patients and their families must include its waxing and waning nature that can be managed by therapeutic interventions, compliance monitoring and feedback, and it should not reflect either moral weakness or character flaws leading to stigmatisation issue. Counseling; lifestyle changes like exercise, decreasing alcohol, caffeine, and tobacco consumption; regulating sleep; and controlling external stimuli for sleep improvement are encouraged. As insomnia, acute or chronic, is a norm among patients, PCPs have to understand and monitor its severity. Questions about "sleep hygiene", use of alcohol, daytime sleepiness and problems in functioning can be helpful. Although patients often require short-term pharmacological therapy for their insomnia at the time of initial diagnosis (especially if insomnia is the presenting symptom), or at times of acute exacerbations, the priority of the physician should be helping patients to develop appropriate lifestyle changes that will promote its long-term control. GAD patients often find themselves rehashing problems and unmet expectations, especially during exacerbations, which they find hard to cope with. Simple anxiety coping techniques that help in gaining improved sense of self-control in times of crises can be taught (Culpepper, 2002;Allgulander, 2009; Davidson et al., 2010).

GAD patients deserve effective medical treatment with short and long-term goals. The short-term goals of treatment include reduction in somatic and psychic symptoms, and resolution of insomnia. Long-term goals should include achieving fully functional status that is affected by anxiety, preventing relapses or recurrences, and treatment of comorbid disorders GAD patients suffer from, such as depression. PCPs need to be aware of short and long-term adverse effects of their treatment like worsening of insomnia and agitation, and weight gain and sexual dysfunction, respectively (Culpepper, 2002). 
Pharmacotherapy is the most common treatment option chosen by the physicians that needs to be emphasized as an extended treatment option. There are several treatment guidelines and a general consensus among these guidelines is that the first-line pharmacotherapy for GAD patients should include selective serotonin reuptake inhibitors (SSRIs) or serotoninnorepinephrine reuptake inhibitors (SNRIs) (Katzman, 2009). The SSRIs such as paroxetine, first licensed SSRI for GAD, escitalopram; SNRIs such as venlafaxine, and duloxetine (recently approved in United States for GAD treatment) , buspirone, and benzodiazepins are commonly used agents in primary care (Katzman, 2009; Davidson et al., 2010). Tricyclic antidepressants and monoamine oxidase inhibitors should be reserved for patients not responding other regimens as they have potential for lethal overdose and serious adverse effects. Benzodiazepines are generally recommended for short-term use as they provide immediate relief of insomnia and somatic symptoms; however, those have less effect on psychological symptoms. Their long-term use causes problems of addiction and withdrawal leading conflicts with PCPs. Benzodiazepine use is also problematic for elderly due to the side effects like falling, memory impairment, and loss of coordination, drowsiness and confusion. PCPs have to be aware of adverse effects of these substances when used with other drugs like hypnotics, sedating antidepressants, opiate analgesics, anticonvulsants, anti histamines, and alcohol. (Culpepper, 2002; Davidson et al., 2010). Buspirone has disadvantages of delayed onset effect, short half-life, failure to treat comorbid anxiety or depressive disorders, and is generally less effective than the benzodiazepines, so it is not recommended as first-line treatment for GAD. Hydroxyzine, an antihistaminic, was also reported to be effective for GAD. Due to its sedating and anticholinergic effects, slow onset of action, and lack of efficacy for its comorbids, it is not preferred as first-line treatment (Davidson et al., 2010). SSRIs and an SNRI, venlafaxine are all equally efficient for treating GAD. When choosing between them, some parameters that need to be considered are cost and generic availability, the risk of breakthrough symptoms when a dose is missed, the ease of titration, the potential interaction with other drugs, and adverse effects. Venlafaxine, the first approved drug for GAD, is a valuable first-line treatment option for PCPs, indicated for long treatment of GAD, and also effective in comorbid depressive symptoms and depression. Its dosage should be titrated to minimise its adverse effects, such as nausea, dizziness, dry month, sleepiness. Patients should be monitored for a significant increase in blood pressure. Adverse effects include orthostatic hypotension, sweating, and urinary hesitancy (Culpepper, 2002; Davidson et al., 2010). Paroxetine has the disadvantages of longterm weight gain, and withdrawal symptoms in case of dose omission. Evidence is emerging for atypical antipsychotics that they are effective in the treatment of patients with anxiety disorders both as monotherapy and augmentation to the standard treatment (Katzman, 2009; Davidson et al., 2010).

There are different psychotherapy approaches and the most commonly used one is Cognitive-Behavioural Therapy (CBT). CBT includes psychoeducation, symptom management techniques, cognitive restructuring, exposure to anxiety producing events, relaxation training, and self-monitoring as important first-line treatment options in GAD with the advantage of patient preference and lack of adverse effects (Katzman, 2009). Although it was demonstrated that CBT is the most effective psychological treatment for GAD, clinical response for the treatment was found at less than $50 \%$ (Davidson et al., 2010). It is difficult to deliver the treatment adequately, as it needs extensive training of the therapist and time to take effect (van Boeijen et al., 2005). Although it is not possible for PCPs to provide CBT to their GAD patients they should act as guides in selection of 
experienced CBT therapists, prescribe and monitor pharmacotherapy in coordination with the patient's therapist, and help patients to use the therapeutic approaches of CBT following the conclusion of formal therapy, especially when they meet new stressors. Attempts have been made for CBT modifications such as 'self-help' approaches including 'bibliotherapy' (written format, self-help manuals), communication with peers, computerised systems, using a telephone and interactive voice response (Bower et al., 2001; van Boeijen et al., 2005a, Allgulander, 2009). Bower et al. provided some preliminary evidence about self-help packages may offer some clinical advantages over routine primary care for anxiety and depressive disorders and van Boeijen et al. concluded that with more time spent on guidance on the use of the self-help manual, positive results can be achieved for even the patients with longstanding anxiety symptoms (Bower et al., 2001; van Boeijen et al., 2005a). It was shown in the study that the primary care patients with GAD may be treated by their GPs as effectively as after their referral to a psychiatric outpatient clinic, and self-help manual usage is easier for GPs than less structured guidelines resulting in fewer referrals to specialized care (van Boeijen et al., 2005b). Principles of CBT can also be useful while counselling with "high utilisers" and patients suffering acute exacerbations. PCPs can help patients identify and correct their misconceptions about events they perceive as worrying and automatic thought processes that underline the misconceptions, and to develop selfregulation of these thoughts, feelings, and behaviours, namely cognitive restructuring (Culpepper, 2002). Another form of promising psychotherapy for GAD patients is the "wellbeing therapy" (Davidson et al., 2010).

A recent study published recommended a "unified approach" to the diagnosis, care management, and pharmacotherapy of primary care anxiety addressing the difficulty of assessing and managing multiple anxiety disorders in the primary care setting. The method emphasizes the identification of other medical or psychiatric comorbidities that can complicate the treatment, an approach for the initial education of the patient and discussion about treatment based on motivational interviewing, valid monitoring, an algorithmic approach for the selection of initial pharmacotherapy, and selection of alternative or adjunctive treatments (Roy-Byrne et al., 2009). This approach as a part of flexible treatment-delivery model, namely CALM ("Coordinated Anxiety Learning and Management"), was studied as a randomised controlled trial and compared with usual care in primary care settings. Roy-Byrne concluded that for patients with anxiety disorders treated by PCPs, a collaborative care resulted in greater improvement in managing anxiety symptoms and functional disability, and increasing quality of care over 18 months (Roy-Byrne et al., 2010).

\section{Quality of care in primary care}

Young et al., defining poor-quality care as no care or inappropriate care in their study, showed that $80.5 \%$ of individuals visiting only PCPs had a poor-quality of care. Patients receiving poor-quality care from PCPs were less likely to report evaluation of mental health, recommendation of psychiatric medication, or referral to a mental health specialist. Patients not receiving appropriate care were most often most often from the following groups: men, black, older adults, young adults, people with only primary or no education, and people of lower socioeconomic status (Young et al., 2001). Stein et al. found that the level of appropriate care for anxiety disorders was moderate to low in patients that attended a university affiliated primary care practice. Nearly one third of the 
patients had received counselling from their PCPs, with less than $10 \%$ receiving help from a mental health professional, including multiple elements of CBT. Approximately $40 \%$ of patients underwent appropriate pharmacotherapy in the preceding three months. However, only $25 \%$ received it at a minimally adequate dose and duration. Different studies determined different factors that had effects on receiving appropriate treatment. In one, the patients with comorbid depression and/or medical illnesses were more likely to receive appropriate treatment, while patients from ethnic minorities were less likely (Stein et al., 2004). Hyde et al., found that with greater severity of disease, measured by total score of GHQ-12, male patients had a significantly increased probability of receiving active treatment (Hyde et al, 2005). Weisberg et al. also emphasised in their study that racial/ethnic minority groups were less likely to be receiving treatments from psychiatrists (Weisberg et al., 2007).

Young et al. discussed that there are many factors that can contribute to improper care and management of depressive and anxiety disorders. These include the perceived need, willingness for care, insurance coverage, and detection by physicians, and knowledge and beliefs of health care providers regarding effective treatment (Young et al., 2001). In a study carried out with a subsample of ESEMeD, the percentage of patients receiving adequate treatment in specialised and general medical care were $31.8 \%$ and $30.5 \%$, respectively. In this study factors associated with appropriate treatment were living in a large city, a high education level, and a good self-rated health state (Fernándes et al., 2006). Weisberg et al. pointed out that primary care patient who were not receiving pharmacotherapy for their anxiety disorder claimed two main reasons for this. One was that their doctor never recommended treatment and the other was that they did not believe in medication for emotional problems. In the same study the most commonly claimed reasons for not receiving psychotherapy were patients' lack of belief in psychotherapy, and their ignorance about the treatability of their emotional problems. Other barriers frequently mentioned for psychotherapy, but rarely for pharmacotherapy were cost, convenience, not knowing how to get into therapy (Weisberg et al., 2007). All of these seem to have a common base with barriers for accurate diagnosis.

In a study searching for the cause and length of delays in care of specific subcategories of anxiety disorders, it was found that GAD patients seek help from their family physician or his/her equivalent 10.3 months after showing symptoms and visit an anxiety clinic for 83.8 months after showing symptoms (Wagnet et al., 2006).

\section{Interventions for primary care}

It is obvious that problems encountered in diagnosis and management of GAD in PHC is multifaceted and multiphase and there is a need of integration of mental health in primary care. Primary care has the potential to reach the whole community as being the first point of contact and patient-centred interaction depending on long-lasting, trust based communication. This is also a support for the continuity of care, which is especially important for GAD patients having relapses and remissions. These advantages of primary care, along with all its handicaps can facilitate an integrated treatment approach (Rakel, 2007).

In a systematic review evaluating the effectiveness of interventions aimed to improve recognition, diagnosis and management of patients with anxiety disorders, it was concluded that the most promising choice of care in general practice is a combination of professional interventions with organisational interventions, including an education 
component where an external expert such as a nurse therapist or a psychologist is introduced (Heideman et al., 2005).

A report prepared by WHO and WONCA (World Organization of Family Doctors) put forward the principles for the integration of mental health into primary care that are, naturally, appropriate for GAD. Some of these principles are supported in this paper, especially for GAD. These include: adequate training of primary care workers, limited and doable tasks for mental care, support to primary care by specialist mental health professionals and facilities, access to essential psychotropic medications in primary care, and collaboration of PCPs with other government non-health sectors, nongovernmental organizations (WHO\&WONCA, 2008).

\section{Conclusions}

GAD is the most prevalent anxiety disorder in primary care. Its comorbidity is welldocumented, leading higher economic burden and a decrease in quality of life. Primary care settings are the best way of ensuring that GAD patients can get the care they need as they are accessible, affordable, acceptable, and cost-effective. Barriers for diagnosis and management of GAD in primary care include: nature of disease, patient- and physicianrelated factors, and societal factors such as stigmatisation. The proper management of GAD is also multifaceted, and multistage, which means that PCPs needs appropriate counselling with guidelines and screening tools. Primary care is the place that can ensure patients achieve care in a holistic manner, addressing both their physical and mental health needs. Advantages of primary care have to be taken into account for quality improvement programs that will be implemented to enhance awareness and utilization of appropriate treatment options.

\section{Future research efforts}

- Researches accurately reflecting, and modelling the complexities of recognition in primary care

- Models that increase patients' and society's awareness and physicians' recognition of GAD

- Effect of patients' attribution styles on the physician's recognition and recommendations needed to be studied for solutions to cope with the situation and achieving a more accurate diagnosis

- Development of reliable and easy to use screening tools/instruments, and increased frequency of their use in primary care setting

- Professional and organisational interventions for improvement of diagnosis and treatment of GAD need to be studied with a long-term follow up

- Evidence to support the therapeutic value of combined treatments for more complex cases

- Data showing the degree of unmet needs for treatment of GAD patients with economic burden, due to inappropriate treatment and inadequate inpatient and outpatient interventions

- Studies that provide a chance to understand the reasons underlying low rates of quality care, and implementation of measures to improve them. 


\section{References}

Allgulander C. (2006). Generalized anxiety disorder: What are we missing? European Neuropsychopharmacology. Vol.16, Suppl No.2, (May 2006), pp. S101-108, ISSN: 0924977X.

Allgulander C. (2009). Generalized anxiety disorder: between now and DSM-V. Psychiatric Clinics of North America. Vol.32, No.3, (September 2009), pp. 611-28, ISSN 0193-953X.

Alonso J, Angermeyer MC, Bernert S, Bruffaerts R, Brugha TS, Bryson H, de Girolamo G, Graaf R, Demyttenaere K, Gasquet I, Haro JM, Katz SJ, Kessler RC, Kovess V, Lépine JP, Ormel J, Polidori G, Russo LJ, Vilagut G, Almansa J, Arbabzadeh-Bouchez S, Autonell J, Bernal M, Buist-Bouwman MA, Codony M, Domingo-Salvany A, Ferrer M, Joo SS, Martínez-Alonso M, Matschinger H, Mazzi F, Morgan Z, Morosini P, Palacín C, Romera B, Taub N, Vollebergh WA; ESEMeD/MHEDEA 2000 Investigators, European Study of the Epidemiology of Mental Disorders (ESEMeD) Project. (2004). Disability and quality of life impact of mental disorders in Europe: results from the European Study of the Epidemiology of Mental Disorders (ESEMeD) project. Acta Psychiatrica Scandinavica. Suppl. 420, pp. 38-46, ISSN 0001-690X.

American Psychiatric Association. (2000). Diagnostic and statistical manuel of mental disordersTR, $4^{\text {th }}$ ed. American Psychiatric Association, Washington DC, ISBN: 0890420254

Andlin-Sobocki P, Wittchen HU. (2005). Cost of anxiety disorders in Europe. European Journal of Neurology. Vol.12, Supplement No. 1, (June 2005), pp.39-44, ISSN: 1468-1331.

Ansseau M, Dierick M, Buntinkx F, Cnockaert P, De Smedt J, Van Den Haute M, Vander Mijnsbrugge D. (2004). High prevalence of mental disorders in primary care. Journal of Affective Disorders. Vol.78, No.1, (January 2004), pp. 78.49-55, ISSN 0165-0327.

Ansseau M, Fischler B, Dierick M, Mignon A, Leyman S. Prevalance and impact of generalized anxiety disorder and major depression in primary care in Belgium and Luxemburg: the GADIS study care in Belgium and Luxemburg: the GADIS study. European Psychiatry. Vol.20, No.3, (May 2005), pp. 229-235, ISSN: 0924-9338.

Bijl RV, Ravelli A, van Zessen G. (1998). Prevalence of psychiatric disorder in the general population: results of The Netherlands Mental Health Survey and Incidence Study (NEMESIS). Social Psychiatry and Psychiatric Epidemiology. Vol. 33, No. 12, (December 1998), pp. 587-95, ISSN: 1433-9285.

Bélanger L, Ladouceur R, Morin CM. (2005). Generalized anxiety disorder and health care use. Canadian Family Physician. Vol.51, No.10, (October 2005), pp. 1362-3, ISSN: 1715-5258.

Bower P, Richards D, Lovell K. (2001). The clinical and cost-effectiveness of self-help treatments for anxiety and depressive disorders in primary care: a systematic review. The British Journal of General Practice. Vol. 51, No. 471, (October 2001), pp. 838-45, ISSN: 0960-1643.

Cape J, McCulloch Y. (1999). Patients' reasons for not presenting emotional problems in general practice consultations. The British Journal of General Practice. Vol.49, No.448, (November 1999), pp. 875-9, ISSN: 0960-1643.

Carter RM, Wittchen HU, Pfister H, Kessler RC. (2001). One-year prevalence of subthreshold and threshold DSM-IV generalized anxiety disorder in a nationally representative sample. Depression and Anxiety. Vol. 13, No. 2, (March 2001), pp. 78-88, ISSN: 15206394. 
Culpepper L. (2002). Generalized anxiety disorder in primary care: emerging issues in management and treatment. The Journal of Clinical Psychiatry. Vol. 63, Suppl.8 (2002), pp. 35-42, ISSN: 1555-2101.

Davidson JR, Feltner DE, Dugar A. (2010). Management of generalized anxiety disorder in primary care: identifying the challenges and unmet needs. The Primary Care Companion to the Journal of Clinical Psychiatry. Vol.12, No.2, (2010).

Fernández A, Haro JM, Codony M, Vilagut G, Martínez-Alonso M, Autonell J, SalvadorCarulla L, Ayuso-Mateos JL, Fullana MA, Alonso J. (2006). Treatment adequacy of anxiety and depressive disorders: primary versus specialised care in Spain. Journal of Affective Disorders. Vol.96, No.1-2, (November 2006), pp. 9-20, ISSN 0165-0327.

Harman JS, Rollman BL, Hanusa BH, Lenze EJ, Shear MK. (2005). Physician office visits of adults for anxiety disorders in the United States, 1985-1998. Journal of General Internal Medicine. Vol.17, No.3, (March 2002), pp. 165-72, ISSN: 1525-1497.

Heideman J, van Rijswijk E, van Lin N, de Loos S, Laurant M, Wensing M, van de Lisdonk E, Grol R. (2005). Interventions to improve management of anxiety disorders in general practice: a systematic review. The British Journal of General Practice. Vol.55, No.520 (November 2005), pp. 867-74, ISSN: 0960-1643.

Hyde J, Evans J, Sharp D, Croudace T, Harrison G, Lewis G, Araya R. (2005). Deciding who gets treatment for depression and anxiety: a study of consecutive GP attenders. The British Journal of General Practice. Vol.55, No.520, (November 2005), pp.846-53, ISSN: 0960-1643.

Kadam UT, Croft P, McLeod J, Hutchinson M. (2001). A qualitative study of patients' views on anxiety and depression. The British Journal of General Practice. Vol.51, No. 466, (May 2001), pp. 375-80, ISSN: 0960-1643.

Katzman MA. Current considerations in the treatment of generalized anxiety disorder. (2009). CNS Drugs. Vol.23, No.2, (February 2009), pp. 103-20, ISSN: 1179-1934.

Kessler D, Bennewith O, Lewis G, Sharp D. (2002). Detection of depression and anxiety in primary care: follow up study. The British Medical Journal. Vol.235, No.7371, (November 2002), pp. 1016-7, ISSN: 1468-5833.

Kessler D, Lloyd K, Lewis G, Gray DP. (1999). Cross sectional study of symptom attribution and recognition of depression and anxiety in primary care. The British Medical Journal. Vol.318, No.7181 (February 1999), pp. 436-9, ISSN: 1468-5833.

Kroenke K, Jackson JL, Chamberlin J. (1997). Depressive and anxiety disorders in patients presenting with physical complaints: clinical predictors and outcome. The American Journal of Medicine. Vol.103, No.5, (November 1997), pp. 339-47, ISSN: 0002-9343.

Kroenke K, Spitzer RL, Williams JB, Monahan PO, Löwe B. (2007). Anxiety disorders in primary care: prevalence, impairment, comorbidity, and detection. Annals of Internal Medicine. Vol.146, No.5 (March 2007), pp. 317-325, ISSN: 1539-3704.

Lieb R, Becker E, Altamura C. (2005). The epidemiology of generalized anxiety disorder in Europe. European Neuropsychopharmacology Vol.15, No.4, (August 2005), pp. 445-452, ISSN: 0924-977X.

Löwe B, Spitzer RL, Williams JB, Mussell M, Schellberg D, Kroenke K. (2008). Depression, anxiety and somatization in primary care: syndrome overlap and functional impairment. General Hospital Psychiatry. Vol.30, No.3, (May 2008, pp. 191-9, ISSN: 0163-8343.

Maier W, Gänsicke M, Freyberger HJ, Linz M, Heun R, Lecrubier Y. (2000). Generalized anxiety disorder (ICD-10) in primary care from a cross-cultural perspective: a valid 
diagnostic entity? Acta Psychiatrica Scandinavica. Vol.101, No.1 (January 2000), pp. 29-36, ISSN: 1600-0447.

Means-Christensen AJ, Sherbourne CD, Roy-Byrne PP, Craske MG, Stein MB. (2006). Using five questions to screen for five common mental disorders in primary care: diagnostic accuracy of the Anxiety and Depression Detector. General Hospital Psychiatry. Vol.28, No.2, (March-April 2006), pp. 108-18, ISSN: 0163-8343.

Mergl R, Seidscheck I, Allgaier AK, Möller HJ, Hegerl U, Henkel V. (2007). Depressive, anxiety, and somatoform disorders in primary care: prevalence and recognition. Depression and Anxiety. Vol.24, No.3, (April 2007), pp. 185-95, ISSN: 1520-6394 .

Olfson M, Shea S, Feder A, Fuentes M, Nomura Y, Gameroff M, Weissman MM. (2000). Prevalance of anxiety, depression, and substance use disorders in an urban general medicine practice. Archieves of Family Medicine. Vol.9, No.9 (September-October 2000), pp. 876-883, ISSN: 1063-3987.

Olfson M, Gameroff MJ. (2007). Generalized anxiety disorder, somatic pain and health care costs. General Hospital Psychiatry. Vol.29, No.4, (July-August 2007), pp. 310-6, ISSN: 0163-8343.

Robert E Rakel. (2007). Rakel Textbook of Family Medicine. Printed in China, ISBN: 139781 416024675

Revicki DA, Brandenburg N, Matza L, Hornbrook MC, Feeny D. (2008). Health-related quality of life and utilities in primary-care patients with generalized anxiety disorder. Quality of Life Research. Vol.17, No.10, (December 2008), pp. 1285-94, ISSN: 0962-9343.

Rodriguez BF, Weisberg RB, Pagano ME, Machan JT, Culpepper L, Keller MB. (2004). Frequency and patterns of psychiatric comorbidity in a sample of primary care patients with anxiety disorders. Comprehensive Psychiatry. Vol.45, No.2, (MarchApril 2004), pp. 129-37, ISSN: 0010-440X.

Rollman BL, Belnap BH, Mazumdar S, Zhu F, Kroenke K, Schulberg HC, Katherine Shear M. (2005). Symptomatic severity of PRIME-MD diagnosed episodes of panic and generalized anxiety disorder in primary care. Journal of General Internal Medicine. Vol.20, No.7, (July 2005), pp. 623-8, ISSN: 1525-1497.

Roy-Byrne PP, Wagner A. Primary care perspectives on generalized anxiety disorder. Journal of Clinical Psychiatry. Vol.65, No.13, (2004), pp. 20-6, ISSN: 1555-2101.

Roy-Byrne P, Veitengruber JP, Bystritsky A, Edlund MJ, Sullivan G, Craske MG, Welch SS, Rose R, Stein MB. (2009). Brief intervention for anxiety in primary care patients. Journal of the American Board of Family Medicine. Vol.22, No.2, (March-April 2009), pp. 175-86, ISSN: 1558-7118.

Roy-Byrne P, Craske MG, Sullivan G, Rose RD, Edlund MJ, Lang AJ, Bystritsky A, Welch SS, Chavira DA, Golinelli D, Campbell-Sills L, Sherbourne CD, Stein MB. (2010). Delivery of evidence-based treatment for multiple anxiety disorders in primary care: a randomized controlled trial. JAMA. Vol.303, No.19, (May 2010), pp. 1921-8, ISSN: 0098-7484.

Ruiz MA, Zamorano E, García-Campayo J, Pardo A, Freire O, Rejas J. Validity of the GAD-7 scale as an outcome measure of disability in patients with generalized anxiety disorders in primary care. Journal of Affective Disorders. Vol.128, No.3, (February 2011), pp. 277-86, ISSN 0165-0327.

Sherbourne CD, Sullivan G, Craske MG, Roy-Byrne P, Golinelli D, Rose RD, Chavira DA, Bystritsky A, Stein MB. Functioning and disability levels in primary care out- 
patients with one or more anxiety disorders. (2010). Psychological Medicine. Vol.40, No.12 (December 2010), pp. 2059-68, ISSN: 0033-2917.

Serrano-Blanco A, Palao DJ, Luciano JV, Pinto-Meza A, Luján L, Fernández A, Roura P, Bertsch J, Mercader M, Haro JM. (2010). Prevalence of mental disorders in primary care: results from the diagnosis and treatment of mental disorders in primary care study (DASMAP). Social Psychiatry Psychiatric Epidemiology. Vol.45, No.2 (February 2010), pp. 201-10, ISSN: 1433-9285.

Shearer SL. (2007). Recent advances in the understanding and treatment of anxiety disorders. Primary Care. Vol.34, No.3, (September 2007), pp. 475-504, ISSN: 1558-299X.

Stein MB. Attending to anxiety disorders in primary care. (2003). Journal of Clinical Psychiatry. Vol.64, Supplement 15, (2003), pp. 35-9, ISSN: 1555-2101.

Stein MB, Sherbourne CD, Craske MG, Means-Christensen A, Bystritsky A, Katon W, Sullivan G, Roy-Byrne PP. (2004). Quality of care for primary care patients with anxiety disorders. The American Journal of Psychiatry. Vol.161, No.12 (December 2004), pp. 2230-7, ISSN: 0002-953X.

Tylee A, Walters P. (2007). Underrecognition of anxiety and mood disorders in primary care: why does the problem exist and what can be done? Journal of Clinical Psychiatry. Vol.68, Supplement 2, (2007), pp. 27-30, ISSN 0165-0327.

Ustun TB, Sartorius N. Mental Illness in General Health Care, An International Study. England: Wiley; 1995. pp. 39-55, ISBN: 0471954918.

van Boeijen CA, van Balkom AJ, van Oppen P, Blankenstein N, Cherpanath A, van Dyck R. (2005a). Efficacy of self-help manuals for anxiety disorders in primary care: a systematic review. Family Practice. Vol.22, No.2, (April 2005), pp. 192-6, ISSN: 0263-2136.

van Boeijen CA, van Oppen P, van Balkom AJ, Visser S, Kempe PT, Blankenstein N, van Dyck R. (2005b). Treatment of anxiety disorders in primary care practice: a randomised controlled trial. The British Journal of General Practice. Vol.55, No.519, (October 2005), pp. 763-9, ISSN: 0960-1643.

Wagner R, Silove D, Marnane C, Rouen D. (2006). Delays in referral of patients with social phobia, panic disorder and generalized anxiety disorder attending a specialist anxiety clinic. Journal of Anxiety Disorders. Vol.20, No.3, (2006), pp. 363-71, ISSN: 0887-6185.

Weisberg RB, Dyck I, Culpepper L, Keller MB. (2007). Psychiatric treatment in primary care patients with anxiety disorders: a comparison of care received from primary care providers and psychiatrists. The American Journal of Psychiatry. Vol.164, No.2, (February 2007), pp. 276-82, ISSN: 0002-953X.

Wittchen H-U, Hoyer J. Generalized Anxiety Disorder: Nature and Course. (2001). Journal of Clinical Psychiatry Vol.62, No.11, (2001), pp. 15-18, ISSN: 1555-2101.

Wittchen HU, Kessler RC, Beesdo K, Krause P, Höfler M, Hoyer J. (2002). Generalized anxiety and depression in primary care: prevalence, recognition, and management. Journal of Clinical Psychiatry. Vol.63, Supplement No. 8 (2002), pp.24-34, ISSN: 0887-6185.

World Health Organization: ICD-10, Version 2007. http://apps.who.int/classifications/apps/icd/icd10online/.

World Health Organization and World Organization of Family Doctors (WONCA) 2008. Integrating Mental Health into Primary Care: A Global Perspective. Printed in Singapore, ISBN: 9789241563680.

Young AS, Klap R, Sherbourne CD, Wells KB. (2001). The quality of care for depressive and anxiety disorders in the United States. Archieves of General Psychiatry. Vol.58, No.1, (January 2001), pp. 55-61, ISSN: 0003-990X. 


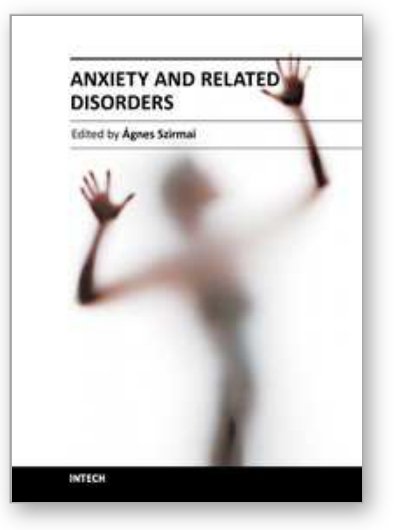

\author{
Anxiety and Related Disorders \\ Edited by Dr. Ãgnes Szirmai
}

ISBN 978-953-307-254-8

Hard cover, 292 pages

Publisher InTech

Published online 29, August, 2011

Published in print edition August, 2011

Anxiety disorders are one of the most common psychiatric disorders worldwide and many aspects of anxiety can be observed. Anxious patients often consult primary care physicians for their treatment, but in most cases they do not accept the diagnosis of anxiety disorder. Anxiety is a symptom that could be seen in many organic disorders and can accompany almost any psychiatric disorder. Anxiety disorders are frequent and are associated with significant distress and dysfunction. Stigmatization is an important factor in insufficient diagnosis. The problems of anxiety cover all fields of life. This book intends to describe the epidemiological aspects and the main co-morbidities and consecutive diseases of the anxiety disorders.

\title{
How to reference
}

In order to correctly reference this scholarly work, feel free to copy and paste the following:

Mehtap Kartal (2011). Challenges and Opportunities in Diagnosis and Management of Generalized Anxiety Disorder in Primary Care, Anxiety and Related Disorders, Dr. Ãgnes Szirmai (Ed.), ISBN: 978-953-307-254-8, InTech, Available from: http://www.intechopen.com/books/anxiety-and-related-disorders/challenges-andopportunities-in-diagnosis-and-management-of-generalized-anxiety-disorder-in-primary-

\section{INTECH}

open science | open minds

\section{InTech Europe}

University Campus STeP Ri Slavka Krautzeka 83/A 51000 Rijeka, Croatia

Phone: +385 (51) 770447

Fax: +385 (51) 686166 www.intechopen.com

\section{InTech China}

Unit 405, Office Block, Hotel Equatorial Shanghai No.65, Yan An Road (West), Shanghai, 200040, China 中国上海市延安西路65号上海国际贵都大饭店办公楼405单元 Phone: +86-21-62489820

Fax: +86-21-62489821 
(C) 2011 The Author(s). Licensee IntechOpen. This chapter is distributed under the terms of the Creative Commons Attribution-NonCommercialShareAlike-3.0 License, which permits use, distribution and reproduction for non-commercial purposes, provided the original is properly cited and derivative works building on this content are distributed under the same license. 